\title{
Manipulating and Complementing Content Teaching to Maximize Second Language Learning ${ }^{1}$
}

Merrill Swain

\begin{tabular}{ll}
\hline Much current discussion about com- & that not all content teaching is necessarily \\
municative language teaching incorporates & good language teaching, and suggests \\
the notion that second language learning & some ways in which content teaching \\
will be enhanced through its integration & might be organized to enhance second lan- \\
with content learning. This paper argues & guage learning.
\end{tabular}

The purpose of this paper is to suggest that not all content teaching is necessarily good language teaching. I hope to show, by way of examples from French immersion teaching, some ways in which typical content teaching is inadequate as a second language learning environment. And again, by means of examples, I hope to suggest some ways in which content teaching can be manipulated and complemented to enhance its language learning potential.

There are many classrooms in Canada and elsewhere where the learning of content and the learning of a second language are both programme goals. There is at least one major assumption about content teaching that is current in second language theory and pedagogical practices today. The assumption is-because content teaching is considered communicative language teaching par excellence-that through content teaching, second language learning will be enhanced.

This was certainly one of the assumptions underlying the initiation of French immersion programmes. But just as it has come to be recognized in English content classes that learners of non-English backgrounds need the support of ESL classes, so in French immersion classes, the French language arts component is seen to support the language learning of the content class. What goes on in the content class, and the relationship of the language arts component to it, is the focus of this paper.

\section{Content Learning as Language Learning}

My guess is that most of us accept the assumption that second language learning will be enhanced through content learning. However, there are pockets of evidence to suggest that such an assumption may be unwarranted, or at least, needs to be qualified. 
For example, consider the results of an experiment carried out in Hong Kong (Ho, 1985). The first language of the students in the experiment was Cantonese and they had had English as a subject for six years and had been using textbooks written in English in all subjects in the previous year. The students, at the time of the experiment, were in grade 8 , and consisted of the top-performing students in their school. The heart of the experiment was that for five months some of these grade 8 students were taught $60 \%$ of their curriculum totally in English, while other grade 8 students in the same school were taught all their curriculum in Cantonese. Students were randomly assigned to the English-instructed class or to the Cantoneseinstructed class. The same teachers taught in both classes so that, for example, a teacher who taught Science in English to the English-instructed class taught the same lesson the same day to the other students in Cantonese.

Unfortunately, the write-up of the study describes very little about the substance of the tests or the criteria used for evaluating English language performance, but it does indicate that at the end of the fifth month, there were no differences between the two groups in their performance on the English language tests which were given. In other words, five months of instruction in English using the content from a variety of academic subjects did not enhance the learning of English for these grade 8 Hong Kong students.

There are many possible explanations for this finding. For example, none of the teachers were native speakers of English. However, this is not atypical of ESL teachers in many parts of the world; and one would still expect some modest difference in English language performance between the two groups to be found. The explanation I consider most likely concerns the methodology of the presentation of the content.

Of course, I do not know precisely what methodology the teachers in the Hong Kong experiment were actually using, but I am willing to make guesses. My guesses are based on what I observed when I was in Hong Kong for three mơnths in 1985 , on what has been observed in typical content classrooms in the United States (Goodlad, 1984), and what I have observed in typical French immersion classrooms in Canada. The methodology is straightforward: teachers work through a content lesson by asking a lot of questions about something they have presented before, or that the students have read before. The teachers ask questions with particular answers in mind; students' responses are usually fairly short and to the point. This exchange between teachers and their students is rapid and lively as students' hands go up and down. Teachers tend to correct errors of content, and occasionally correct errors of syntax, morphology or pronunciation. Diversions from the main theme of the lesson arising from personal experiences or insights tend not to occur. Written seat-work 
may be assigned where they answer more questions, or fill in blanks. This methodology, I would argue, leaves a lot to be desired from a language learning point of view.

Let us consider an actual lesson in more depth-a few segments taken from a history lesson. The segments are taken from a grade 6 French immersion class, and are presented below in their English translations.

The brief description just provided of typical content classrooms is evident in these translated segments. The teacher explains or summarizes facts and asks questions. The students reply with a word or short sentence. The teacher keeps them 'on-target', content-wise.

The three examples provided below represent only a tiny portion of data we have collected in a recent study (Swain and Carroll, 1987). The study involved observing and tape-recording the full school day of nine grade 3 immersion classes and ten grade 6 immersion classes in Ontario schools. We have transcribed the tape-recordings and have begun to analyze the transcripts from a variety of perspectives. One of the things we have looked at is the frequency and length of student talk in these teacherfronted lessons.

Each student turn in each of the classes was categorized according to its length. They were categorized as 'minimal', 'phrase', 'clause' or 'sustained' in length. Minimal length refers to turns of one or two words in length. Phrase length refers to turns consisting of an adverbial phrase, a nominal phrase or a verb phrase; and clause length refers to a turn consisting of one clause. Any student turn which was longer than a clause was categorized as sustained talk.

The results indicate that there are, on the average, about two student turns per minute. In grade 6 , about $44 \%$ of those are of minimal length. Only $18 \%$ of student turns are sustained in length. Those include occasions when students read aloud. When those occasions are subtracted, then it turns out that only about $14 \%$ of the times that students talk in teacherfronted activities are their utterances longer than a clause. The figures are not much different for the grade 3 classes. As I will argue shortly, opportunities to produce sustained output in the second language are crucial to the second language learning process. Sustained talk provides both opportunities for variety and complexity of language use, and it forces the learner to pay attention to how content is expressed. This suggests that at least some portion of content lessons need to be structured in different ways in order to permit more opportunities for the sustained use of language by students.

Now, let us consider the excerpts from a history lesson taken from a grade 6 immersion class. The lesson is about the Antilles in 1796-what it was like then and the sorts of things that were influencing life at that time. Before actually reading the excerpts, consider two questions. First, 
what will be the most common tense used by the teacher-past, present or future? Secondly, as a language teacher, what would be one reason to teach a historical theme?

I assume that the answer to both of these questions was "the past tense". Now, let us examine what happens when language is used authentically in the content classroom.

(1) T: It (Europe) didn't have sugar cane. Why didn't they have sugar cane? Mary?

S: It's too cold.

T: It's too cold. Another word for 'the weather'?

S: The climate is not good.

(2) T: What do you think? How did these plantations influence life in the Antilles? How do you think that these plantations . . . are going . . . uhm to change . . . life in the Antilles?

(3) T: These people are going to sell their sugar . . rum . . . molasses ... brown sugar. They are going to make money. With the money, they are going to buy clothes, furniture . . . horses . . . carriages . . . all that they want and they are going to bring back to the Antilles . . . one imports . . . the Antilles import . . . Now I want to go back to what John was saying because I thought that that was what he was trying to explain to me. How is it going to change life in the Antilles?

S: Modernize.

$\mathrm{T}$ : OK. We are going to import modern objects ... to the Antilles. $\mathrm{OK}$, it's one way that that's going to influence things. Another . . . Is there another way of influ-- How are the plantations going to influence life in the Antilles?

$S$ : All the slaves and all the different cultures who work on the uhm XXX.

$\mathrm{T}$ : Yes! You have these huge plantations . . . you certainly are going to have some cultures and customs that are . . .

S: Different.

T: Are going to mix together.

Example (1) illustrates one of the teacher's relatively infrequent uses of the past tense in this history lesson. Notice that the student answers in the present tense. The teacher indicates acceptance by her repetition of the phrase, and concentrates on content by asking for a word that will, in her estimation, improve the response.

In the second example, we see the teacher switch from past tense usage in 'How did these plantations influence life in the Antilles?' to future tense usage 'How do you think that these plantations ... are going . . . uhm to change . . . life in the Antilles?' Use of the 'immediate future', that is, the use of the verb 'to go' plus verb to signal action that is just about to 
happen, appears to be one of this teacher's favoured strategies in this lesson. Example (3) is illustrative.

These examples illustrate the conflict that arises between teaching content and teaching language. What the teacher has done by her use of the 'immediate future' is superb from a content teaching point of view. Its use has brought the distant past into the lives of the children, got them involved, and undoubtedly helped them to understand the social and economic principles which this historical unit was intended to demonstrate. However, as a language lesson, these examples illustrate several problems-problems which may arise in any instructional setting based on authentic communication; problems which arise at the interface of language and content teaching.

First, the focus is entirely meaning-oriented. This is, of course, precisely what Krashen (1982) has argued is needed for second language acquisition to occur. He has argued that what learners should do is 'go for meaning'. But, if students are to actually acquire a second language by 'going for meaning', then they have to be engaging, in some way, in some sort of form-function analysis. That is, they will have to be paying attention to the form of the utterance as it is used to express the meaning they are extracting.

However, as Krashen (1982), himself suggests, "In many cases, we do not utilize syntax in understanding-we often get the message with a combination of vocabulary, or lexical information plus extra-linguistic information." (p. 66). In other words, it is possible to comprehend input-to get the message-without a syntactic or, I would add, a morphological analysis of that input. What appears to occur is 'selective listening' (VanPatten, 1985).

Selective attention is illustrated in part of an interview with an ESL speaker shown below (Wenden, 1983).

Q: Are you comfortable with him (the boss)?

A: Yes, he speaks slowly, more slowly than others, so it's easier for me.

Q: Do you ever notice how he says things?

A: When doing business, I don't consider grammar. Mostly I try to get the meaning. It's not necessary to catch all the words. (Wenden, 1983:6)

Other kinds of evidence for selective listening exist. In one study of adult learners of Spanish, VanPatten (1985) isolated instances where learners apparently ignore how something was said to them. The example below is one such instance.

Q: Como estan ellos? (How are they?)

A: Son contento. (They're happy.)

Q: Y ellos, como estan? (And how are they?) 
A: Son contento tambien. (They're happy too.) (VanPatten, 1985:91)

The learner appears not to have attended to the use of the correct copula estar in the interviewer's first question and produced an utterance in which the wrong copula ser was used. In the next question, therefore, the interviewer moved the copula to a more salient position-the sentence final position-but the learner still did not attend to how the interviewer phrased the question.

We have many similar examples from interviews conducted with French immersion students. The next example is illustrative:

Q: Et qu'est-ce que tu ferais si tu gagnais la loterie? Si tu gagnais d'argent?

A: Je vais mettre dans la banque . . (Harley and Swain, 1977:41)

Here the question is asked using the conditional, and the student responds by using the immediate future form.

As VanPatten indicates, there are occasional reports on selective listening throughout the second language acquisition literature. What they all have in common is that "selective listening seems to involve concentrated focus on informational content and not necessarily on how that content was delivered." (1985:91) Additionally, linguistic literature on discourse argues for the notion of a fuzzy, open, non-deterministic syntactic parsing strategy that is used for comprehending discourse but that would be inadequate for producing it (see Clark and Clark, (1977); van Dijk and Kintsch (1983)). Thus, it may be that any grammatical processing involved in comprehension may be quite different from the closed logical system of rules required to produce a grammatical utterance. In other words, we can understand discourse without precise syntactic and morphological knowledge, but we cannot produce it accurately without precise syntactic and morphological knowledge.

Given that this is the case, then one role of the teacher becomes fairly evident: to help learners undertake the sort of form-function analysis needed to be effective and accurate communicators in their second language. This does not imply teaching rules, although it may well be an effective strategy for some aspects of language and for some learners.

What it does imply is that input that will help learners focus their attention on particular form-functional relationships is essential. Providing relevant input will necessarily be contrived: one has first to identify the area of focus, and then contrive contexts in which its use is natural. This will most certainly involve conscious reflection about the relationship between language form and content. I will return to this point later.

An equally important way to help learners focus their attention on particular form-functional relationships is to require them to produce language. If, as has been suggested, learners do not need precise syntactic and morphological knowledge to understand the gist of language input, 
but do need such knowledge for accurate production, then it will be by requiring students to produce, that they will become aware of their grammatical needs (Swain, 1985). Their language production will have to be at more than a phrase or clause level if they are to learn the mechanisms for coherent and accurate discourse.

The second problem illustrated by the history lesson excerpts is closely related to the first (that of the focus being entirely meaning-oriented). In concentrating entirely on meaning, teachers frequently provide learners with inconsistent and possibly random information about their target language use. If the students are engaging in any sort of form-function analysis while listening to their teacher, consider the message relayed to them based on the first two history lesson examples. The message-the hidden grammar lesson for the students-is that past tense, the immediate future and the present tense are interchangeable. In example (1), a student's response in the present tense to a question asked about the past is accepted, in fact, repeated by the teacher, and, in example (2), the teacher switches from past to future within the same context.

As I mentioned earlier, these examples represent only a tiny portion of the data we have collected in an observational study of grade 3 and grade 6 immersion classes. One analysis we have carried out of these data involves the classification and counting of surface level grammatical errors made by the grade 6 immersion students as they interacted with their teachers. For each error, we noted whether the teacher corrected it. We counted both implicit and explicit instances of correction. Our findings show that only $19 \%$ of the grammatical errors students made were corrected, while the remainder were ignored by the teachers. The pattern of correction appears to be determined as much by an 'irritation' factor as by any consistent pedagogical or linguistic factors.

The solution is most definitely not to correct every error each time one is made. There is no research evidence to suggest that such a procedure would be effective, and it would certainly impede the flow of communication. What the most effective correction strategies might be is not clear. Again, I will return to this point below.

The third problem, and one which cannot be inferred from any one individual example, is that what the students hear-the input they receivemay be functionally restricted. Certain uses of language may simply not naturally occur, or may occur fairly infrequently in the classroom setting. When the main source of second language input is the classroom, this problem is particularly serious.

Let me give two examples of what I mean by 'functionally restricted' uses of language. Both examples come from our observational study of French immersion classes. I would ask you to think of possible examples from your own ESL classroom teaching. This is not an easy task. The 
difficulty in doing so, is that you need to think about what is NOT there, not about what IS there. Furthermore, intuitions about one's own language use are frequently inaccurate. One way to start thinking about your own language use in class is to tape yourself teaching for a day. Later, you can listen and relisten to it from a variety of different perspectives.

By 'functionally restricted', I mean that the full functional range of the linguistic item of focus is not used, or is infrequently used. One example is the use of 'vous' and 'tu' by French immersion teachers. We decided to look at this because we found that in tests of sociolinguistic performance, immersion students tended to overuse 'tu' in situations calling for the use of 'vous'-situations such as making a request to an adult. In other words, in formal contexts, 'vous' was underused by immersion students relative to native speakers of the same age. We thought the explanation for this might be linked to the input the students received in class.

The transcripts of the ten grade 6 classes were examined, and all instances of the teachers' uses of 'tu' and 'vous' were counted and classified according to the functions they served. The French pronouns 'tu' and 'vous' carry both grammatical and sociolinguistic information. A number distinction may be signalled by the use of the singular 'tu' versus plural 'vous'. A sociolinguistic distinction may be manifested in the familiar 'tu' versus the formal 'vous' which is a marker of respect or politeness.

If we look only at form, then no explanation for the immersion students' results emerge. That is to say, the transcripts reveal that 'tu' and 'vous' are used about equally often by immersion teachers on the average, each roughly about once a minute. When we look at function, however, the picture changes dramatically. It turns out that there are very few occurrences of 'vous' where it is used by teachers as a marker of politeness or deference: less than one instance per class.

The second example of functionally restricted language use in immersion classes involves the use of verb tenses. We decided to look at the verb usage of teachers because correct use of non-present tenses is an area of continuing difficulty among immersion students. Among our findings is that students tend to overuse the passé composé, doing so in contexts where the imperfect should be used. Furthermore, the imperfect is rarely used with action verbs. We have also found that even at grade 10 , immersion students correctly produce the conditional only a little more than half the time in obligatory contexts (Harley and Swain, 1985).

Our analysis of the teacher talk is not complete, but what we have found is, I think, interesting in light of the student performance results just mentioned. We began by looking at the frequency with which different verb forms were used by grade 6 immersion teachers. On average, over three-quarters of the verbs used by the grade 6 immersion teachers are in the present or imperative. The proportion of verbs in teacher talk in the 
past tense is approximately $15 \%$; the future tense, $6 \%$; and the conditional tense $3 \%$. Of the verbs used in the past tense, about two-thirds are in the passé composé and one-third in the imperfect. The use of the imperfect was almost completely limited to the verbs avoir, être, fair and vouloir. Its use with action verbs was virtually non-existent. These figures, it seems to us, go a long way towards explaining the second language performance of the students.

To summarize to this point, there are many classrooms in which both the learning of academic content and a second language are-or should be-major goals. In traditional teaching of content, however, the language the teacher uses may be functionally restricted in certain ways, correction of content takes precedence over correction of form in order to preserve the communicative flow, correction of form that does occur is inconsistent in its message, and students' opportunities to engage in extended discourse are limited.

\section{What solutions can be offered?}

Solutions will have to have at least the following four characteristics. First, they will have to ensure that students obtain language input in its full functional range. Secondly, students must be given the opportunity to produce language in its full functional range. Thirdly, there will have to be a way of providing consistent and helpful feedback to learners about their language errors. Fourthly, any solution will have to help learners attend to and act on their language weaknesses.

Perhaps it is best to begin by suggesting what are not solutions.

First, it is not a solution to suggest that teachers change their language use in teaching content. The language that is used is authentic-it represents functionally motivated language. But is is a solution to ask teachers to be aware of their language use so that they can engineer contexts which demand specific and otherwise infrequent uses of language.

As we saw in the history lesson, the teacher's use of the immediate future was strongly motivated on pedagogical grounds. Teaching the lesson using the past tense would have had the effect of distancing the events, and removing them from the immediate reality of the students. The solution is not to force language into content, but to explore content sufficiently so that language in its full range emerges. That takes time, and will only occur over a range of activities, topics and subjects.

Secondly, it is not a solution to correct all the language errors learners make during the content class. The flow of communication would quickly grind to a halt. The fact of the matter is that we do not know what error correction strategies might be most effective. There is surprisingly little 
research data on this important issue, and it is an area ripe for systematic study.

In the typical content class, with student talk and writing being as restricted as it is, students do not have to work at getting their meaning across accurately, coherently and appropriately. However, in the activities which I will discuss shortly, students are producing language for real audiences and a specific purpose. They are motivated to create their intended meaning precisely which involves grammatical accuracy, coherent discourse, and appropriate register.

Error correction derives its consistency from the stage in an activity in which it occurs. Students come to understand that there is a stage of 'spontaneous production' during which they generate text that will need to proceed through further stages of revision and editing before it is 'publicly presentable'. Through these stages of revision and editing, self and peer monitoring are as important as teacher feedback. At the same time, there will be an important role for the teacher since consistency in error correction also derives from the questions which initiate the process. That is to say, the questions which motivate error correction are not "Wrong! Repeat after me", but rather along the lines of "Do you mean this, or do you mean that? It's not clear from what you've said." Or, "it's not clear from the way you've written this." In the immersion study, teachers spent only minimal amounts of observed time asking students what they intended in producing a specific utterance or in writing a text. Yet surely there is pedagogic value in systematically encouraging students to reflect on what they want to say and then helping them to make an appropriate and accurate choice of target language forms-to produce "comprehensible output" (Swain, 1985).

The needs of content learners as language learners argue for limiting the sort of content teaching observed in the history lesson, and increasing the opportunities for learners to hear and use language over a much wider range of activities within the topics and subjects to be covered. Moving in this direction would be to recognize both the need of using language for content learning and of using content for language learning.

\section{Examples of Content Teaching}

Examples of content teaching which take into account the needs of their learners as language learners can be found in some classes, schools, and Boards of Education across Canada. In Vancouver, for example, one of the most interesting and one of the few systematic curricular attempts to integrate content and language teaching for ESL learners is underway. The project team, under the leadership of Bernard Mohan and Margaret Early, are working with a group of teachers in the Vancouver School Board. 
Together they are preparing an activity-based content curriculum that will develop the language that is needed for academic content; for example, the language of description, sequence and choice; the language of classification, principles and evaluation.

Many other examples of content teaching adapted to the needs of second language learners can be found. The approaches taken have been twopronged. The methodology of the content class itself has been modified to incorporate activities that demand extended use of written and oral language by students across a wide range of functions. Consider, for example, the history lesson on the Antilles. The teacher was trying to introduce the concepts of imports and exports; she was trying to show that life changed because of the flow of goods, and to indicate ways in which life changed as a result. A number of activities the students might undertake come to mind: For example, source books could be read, skits could be written and acted out, recipes using local Antilles' products could be located or concocted, descriptions of imported products could be written, advertisements could be created, and so on. Groups of students could research different stages of the importing exporting process: finding buyers, preparing the product, packaging the product, managing staff, shipping, dock handling, and delivering. Each group could prepare descriptions of what needs to be done, identify problems and how to deal with them, write the needed letters, list the individuals that need to be contacted, and so on. Eventually each group could compare their findings with other groups.

But suppose that the teacher wanted to focus specifically on the use of the past tense. She might then ask students, for example, to imagine a situation where the goods ordered by a wealthy plantation owner had been paid for, but it was long after the agreed upon arrival date and the goods had not yet arrived. The task of each student is to write a letter to the importer inquiring about the order. Language such as "I ordered $\mathrm{X}$ on ..., The order consisted of ..." will be required. The letters could be sent to a classmate who must respond as the importer. Language such as "It was sent on . . ., It came back badly damaged, I received your payment only last week", and so on will be essential to complete the task. Of course, other tenses may be used, but the teacher may choose to focus only on the accurate use of the past tense in this particular exercise.

Other aspects of language use could be built in. The tone of the plantation owner's letter could be discussed. Is the owner angry, business-like or friendly? What are the language forms that signal his or her state of mind? How should the importer respond? Should he or she respond differently depending on the plantation owner's tone? How can these differences be signalled through language?

The second approach to adapting content teaching to fit the needs of 
language learners has been to complement it with a language arts programme. Here, the language implications of the content classroom activities can be explored in more depth. The Antilles letters could be followed up by other activities involving letter-writing. Letters to friends, letters to request information, letters to complain, letters to order goods, letters to invite, letters to refuse invitations, and so on, could be written. Differences in style, the linguistic means by which politeness is expressed, the language of requests are matters which the students could explore. There is conscious reflection on the relationship between language form and meaning. Not only might the students write letters themselves to real individuals, but they might bring in letters sent to their parents, including the usual collection of junk mail for comments and analyses.

Recently I spent some time in Fair Oaks Elementary School, a school in Redwood City in California. The school is located in a low income, high minority, industrial area where Spanish is the primary language of most students. Many students, prior to the introduction of their current programme four years ago, tested considerably below the fiftieth percentile on national tests in reading and language. Scores are now considerably higher, and the absenteeism rate is the lowest in the District.

The school describes itself as a bilingual, whole language school. In a brochure that the principal hands out to visitors, it says "Fair Oaks is a place where visitors can observe children . . . using reading and writing to learn about the world, using real books and writing real stories, discovering how to spell by writing and reading, critiquing each other's writings, (and) revising their work based on peer conferences ....". The brochure also point out that Fair Oaks is a place where visitors can observe "teachers ... who read aloud to students daily from a variety of books with rich language and complex ideas, (and) ... whose instructional practices reflect their knowledge that . . . language skill development is embedded in genuine reading and writing, (and that) language is acquired through using it rather than practicing its separate parts . . .". School staff proudly point to the fact that no basal readers are found in the classrooms. Rather, children are reading literature from published books and are creating their own texts.

The school's description of itself is no exaggeration. In fact, it seems to me to be somewhat of an understatement of the richness of language use that occurs in this school. Let me give you some specific examples of language arts activities I observed.

In a grade 1 class, children were working in small groups or individually. A couple of students were lined up to talk to the teacher. There seemed to be no need for discipline as the children were thoroughly absorbed in what they were doing. This state of organized calm was not created overnight, but by the gradual development of routines. The major 
activity while I was in the classroom was journal writing. Journal writing begins with each child writing a diary-type entry into their journal. It ends with a 'published' book. Children were at various stages in the process from journal entry to final publication. Some children were discussing it with their teacher or a fellow student. Some were expanding or correcting what they had written. Others were dictating their story to the teacher who wrote it correctly into a stapled set of pages. Yet others were illustrating their book, deciding who to dedicate their book to, reading their book to others, placing their book in the classroom library, or reading their classmates' books from the library.

At later grade levels, the same process was occurring but students were taking greater and greater responsibility for the production of the language which appeared in their published books. In a grade 5 class, the process was written on the blackboard: choose a topic, write, conference, revise, edit, publish. The rule is that nothing gets published with errors. So when the students consider their work to be ready for publication-when their limits on content and form are reached-the teacher provides them with feedback about their remaining errors of form. This, then, is form corrected in a context created by students where the students, themselves, have signalled that they now need feedback.

In another class, I was shown through a radio broadcasting studio. Every Friday, for half an hour, a group of grade 5 and 6 students go on the air. The programme consists, among other things, of news, stories, jokes, commercials, guest speakers, sensational citizens' awards, school and community announcements, and language arts projects. It is not difficult to see how the preparation of such a show incorporates the four characteristics required of a solution to the problems of traditional content teaching that I have outlined, and how easily the theme of any show could be related to any academic content being taught. The language which is needed for any particular radio show includes a variety of genres, and over time can encompass an endless range of language. Preparation of each script may involve reading newspapers, magazines, community flyers, cookbooks, joke books, content text-books, dictionaries, encyclopedias, and so forth. Knowledgeable resource people have to be decided on, contacted and interviewed. Recordings of the interviews can be made and transcribed. Notes have to be made, and these have to be translated into written texts. Scripts have to be written and perfected. Rehearsals to get it right, have to take place.

On the day I visited, I was shown through the radio studio by the student secretary. She showed me the most recent letter they had received. It was in response to a letter they had written to Queen Elizabeth inviting her to be interviewed on their show. The Queen's letter was a perfect example of a formal letter of polite refusal. Although I did not see the letter that 
went to the Queen, I am sure that its form as well as its content was thoroughly debated and carefully produced.

The students involved are now providing training to students from other schools who wish to begin their own radio station.

In another classroom, I watched cross-age tutoring. Each grade 5 student had been paired with a kindergarten child. The grade 5 students had each chosen a book they thought their child would enjoy, and during their time together, their responsibility was to read the story to their kindergarten child and ask their child questions about the story. The older child wrote down the question, the kindergarten child wrote out a response, and the older child wrote the younger child's meaning underneath his or her response. After the kindergarten children had returned to their classroom, the grade 5 students returned to their desks to reflect individually on their experience by writing field notes. A teacher-led group discussion followed in which several of the students read aloud from their field notes. This was a daily event for the students. Through this activity, the students are given the opportunity for extended language use in both written and spoken form. Through their field notes, the older students learn to reflect on their child's language use and progress. Language becomes a focus of attention and analysis.

To summarize, I have tried to show that typical content teaching is not necessarily good second language teaching. Appropriately, content teaching focusses on comprehending meaning. However, what second language learners need is to focus on form-meaning relationships. Doing so is facilitated through the production of language, whether in written or spoken form. Because the typical question/answer sequence found in content classes tends to elicit short responses of minimal complexity from students, at least part of the content lesson needs to be substituted with activities which demand longer, more complex, and coherent language from the learners.

Focussing on form-meaning relationships is also facilitated through conscious reflection on the relationship between form and meaning in authentic language samples, and in their own language as students struggle to convey precisely their intended meaning. Students need to be guided through this process by engaging them in activities which have been contrived by the teachers to focus the learners' attention, and to naturally elicit particular uses of language.

Content teaching of the question/answer type is limited in the range of form/function relations it naturally brings with it. For this reason, it needs to be complemented with activities that make use of functions otherwise infrequently present. Again, the activities are contrived to ensure the authentic use of language forms.

And finally, content teaching with its focus on meaning, appears to 
provide unsystematic, possibly random feedback to learners about their language errors. It is not clear what strategies of error correction should be adopted. Certainly research has very little to say on the topic. The strategies advocated here, however, are to provide learners with the motivation to use language accurately, coherently and appropriately by writing for, or speaking to, real audiences. Preparation to do so will usually involve a process of revising and editing, and a commitment to an errorfree final product. Error-free implies that learners have conveyed their intended meaning to their own, and their teacher's satisfaction.

Thus, to facilitate second language learning, the typical question/ answer sequence found in much content teaching could be largely substituted with carefully contrived activities, which bring into the classroom authentic language in its full functional range.

\section{NOTES}

1. This paper has had significant input from a number of colleagues. I would like to thank Alister Cumming, Sharon Lapkin, Francis Mangubhai, Norm Rowen and Sandy Schecter for their comments on an earlier draft of this paper. I would like to particularly thank Jean Handscombe and Keith Johnson for spending considerable time well beyond the call of duty in helping me to refine my ideas. They may still not agree with all the content of this paper, but $I$ hope they recognize their impact on it. I also am exceedingly grateful to Carole Urzua and Gloria Norton who made my visit to Fair Oaks Elementary School possible and to the teachers and students who made me so welcome in their classes.

The immersion data reported in this study were collected in the context of a large-scale study on the Development of Bilingual Proficiency awarded by the Social Sciences and Humanities Research Council of Canada (No. 431-79-0003) to Merrill Swain, Patrick Allen, Jim Cummins and Birgit Harley.

Versions of this paper were presented as plenary addresses at the TESL Canada Conference in Vancouver in March, 1987 and at the TESL Ontario Conference in Toronto in November, 1987.

\section{REFERENCES}

Clark, H. and Clark, E., (1977) Psychology and Language: An Introduction to Psycholinguistics. New York: Harcourt Brace Jovanovich.

Goodlad, J.I., (1984) A Place Called School: Prospects for the Future. New York: McGraw Hill.

Harley, B. and Swain, M., (1977) An analysis of verb form and function in the speech of French immersion pupils. Working Papers on Bilingualism, 14, 3146.

Harley, B. and Swain, M., (1985) The interlanguage of immersion students and its implications for second language teaching. In A. Davies and C. Criper (eds.) Interlanguage. Edinburgh: Edinburgh University Press, 291-311. 
Ho, K.K., (1985) The paradox of immersion in a second language. NABE Journal, $10(1), 51-64$.

Krashen, S., (1982) Principles and Practice in Second Language Acquisition. Oxford: Pergamon.

Swain, M., (1985) Communicative competence: Some roles of comprehensible input and comprehensible output in its development. In S. Gass and C. Madden (eds.), Input and Second Language Acquisition. Rowley, Mass.: Newbury House, 235-253.

Swain, M. and Carroll, S., (1987) The immersion observation study, in B. Harley, P. Allen, J. Cummins, and M. Swain (eds.), The Development of Bilingual Proficiency, Final Report, Vol. II on Classroom Treatment. Toronto: Modern Language Centre, 190-263.

van Dijk, T.A. and Kintsch, W., (1983) Strategies of Discourse Comprehension. New York: Academic Press.

VanPatten, B., (1985) Communicative values and information processing in L2 acquisition. In P. Larson, E.L. Judd and D.S. Messerschmitt (eds.), On TESOL '84: A Brave New World for TESOL. Washington, D.C.: TESOL, 89-99.

Wenden, A., (1983) Facilitating autonomy in language learners. TESOL Newsletter, 17(3), 6-7.

\section{THE AUTHOR}

Merrill Swain is Head of the Modern Language Centre at the Ontario Institute for Studies in Education, and Professor in the Department of Curriculum of the same Institution. Her interests include bilingual education and second language learning, teaching and testing. 